\title{
Urea release rate from a scoop of coated pure urea beads: Unified extreme analysis
}

\author{
S.M. Lu, Szu-Lin Chang, Wen-Yu Ku, Hou-Chien Chang, \\ Jiunn-Yau Wang, Duu-Jong Lee* \\ Department of Chemical Engineering, National Taiwan University, Taipei 10617, Taiwan \\ Received 26 March 2007; accepted 10 April 2007
}

\begin{abstract}
Urea release from a scoop of coated beads in a given volume of a well stirred liquid has been investigated analytically and experimentally. A method for determining the fractional cumulative release and fractional release rate curves for the scoop without knowing particle number and radii is presented. The representative $D / K_{\mathrm{b}}$ for a scoop of urea beads spray coated with ethyl cellulose is near $3.5 \times 10^{-8} \mathrm{~cm}^{2} / \mathrm{s}$, and that with cellulose acetate phthalate is near $7 \times 10^{-8} \mathrm{~cm}^{2} / \mathrm{s}$.

(C) 2007 Taiwan Institute of Chemical Engineers. Published by Elsevier B.V. All rights reserved.
\end{abstract}

Keywords: Controlled release; Analysis; Experiment; Spray coated urea beads

\section{Introduction}

Development of controlled release fertilizers (CRFs) is to design device for preventing nutrient loss and enhancing nutrient utilization efficiency by plants (Trenkel, 1997). Polymer coated fertilizer particles were common CRFs whose release characteristics were not sensitive to soil environments.

Mathematical models for single, coated particle were developed for describing release rate of drug with diffusion resistances (Chen and Lee, 2002; Frenning et al., 2003; Li et al., 2006; Liao and Lee, 1997; Lu and Chen, 1993, 1995; Lu, 1994; Shaviv et al., 2003). Kanjickl and Lopina (2004) reviewed some diffusion-controlled models for drug delivery systems. The significant role of diffusional resistances was studied in numerous systems (Chen and Shih, 2006; Huang et al., 2006; Kao and Li, 2006; Kuo and Chung, 2005; Santana and MaciasMachin, 2006; Su et al., 2006).

In fertilizer release experiment or practice from coated beads, it is more often that a scoop of particles, rather than one particle, is used. With particles $1-2 \mathrm{~mm}$ in diameter, the number of particles per release experiment can easily exceed several thousands. Small particles could be coated by

\footnotetext{
* Corresponding author. Tel.: +8862 23625632; fax: +886 223623040.

E-mail address: djlee@ntu.edu.tw (D.-J. Lee).
}

spraying a film forming solution in a bed of fluidized core particles. These particles are usually sieved before and after coating and therefore the particles are alike but not exactly the same. Thus, it will be useful to have a method for the analysis of release data obtained from a scoop of such particles.

Fertilizer release from a large coated pure fertilizer beads in a well stirred liquid has been investigated by Lu and Lee (1992). The scenario analyzed by Lu and Lee (1992) presented an extreme test for release rate of coated particles in soil with limit moisture and no stirring. Here, their analysis has been extended to the case of fertilizer release from a scoop of particles. The results were then applied to analyze experimental release data obtained from a scoop of particles that had been spray coated in a fluidized bed. The method presented herein can be used as the first and extreme estimate to coated bead design and development.

\section{Analysis}

Consider a coated non-swellable particle of radius $a$ containing a pure fertilizer bead of radius $b$ as its core. Fertilizer release from this particle in a liquid is considered to proceed in three stages: (1) for time $t<t_{0}$, liquid infiltration and concentration build up occur in the coating layer, fertilizer released is negligible; (2) For $t_{0} \leq t \leq t_{\mathrm{s}}$, solid is present in the 


\begin{tabular}{|c|c|}
\hline \multicolumn{2}{|c|}{ Nomenclature } \\
\hline$A$ & radius of a coated pure fertilizer bead $(\mathrm{cm})$ \\
\hline$B$ & radius of a coated fertilizer bead $(\mathrm{cm})$ \\
\hline$C$ & $\begin{array}{l}\text { fertilizer concentration: } C_{a, t_{\mathrm{s}}}, \text { at } r=a, t=t_{\mathrm{s}} ; C_{\mathrm{c}} \text {, } \\
\text { in core; } C_{\mathrm{c}, t_{\infty}} \text {, in core, at } t=t_{\infty} ; C_{\mathrm{e}} \text {, in external } \\
\text { liquid; } C_{\mathrm{e}, t_{\infty}}, \text { in external liquid, at } t=t_{\infty} ; C_{\mathrm{sat}} \text {, at } \\
\text { saturation }\left(\mathrm{g} / \mathrm{cm}^{3}\right)\end{array}$ \\
\hline$D$ & $\begin{array}{l}\text { effective diffusivity of fertilizer in coating layer } \\
\left(\mathrm{cm}^{2} / \mathrm{s}\right)\end{array}$ \\
\hline$F$ & defined by Eq. (2) \\
\hline$J$ & mass flux of fertilizer $\left(\mathrm{g} /\left(\mathrm{cm}^{2} \mathrm{~s}\right)\right)$ \\
\hline$K_{i}$ & $\begin{array}{l}\text { partition constant defined by Eqs. (A-2b) and } \\
\text { (A-2c) for } i=a, b\end{array}$ \\
\hline$M_{t}$ & cumulative release at $t ; M_{t_{\mathrm{s}}}$ at $t_{\mathrm{s}} ; M_{t_{\infty}}$ at $t_{\infty}(\mathrm{g})$ \\
\hline$N$ & number of particles per release experiment \\
\hline$N_{1}$ & defined by Eq. (3), (1/s) \\
\hline$\overline{N_{1}}$ & defined by Eq. (11), (1/s) \\
\hline$R$ & radius $(\mathrm{cm})$ \\
\hline$T$ & $\begin{array}{l}\text { time: } t_{0} \text {, the intercept determined by Fig. } 1 ; t_{\mathrm{s}} \text {, } \\
\text { time at which the solid fertilizer in a core dis- } \\
\text { appears; } t_{\infty} \text {, infinite time }(\mathrm{s})\end{array}$ \\
\hline$V$ & $\begin{array}{l}\text { volume: } V_{\mathrm{c}} \text {, core volume; } V_{\mathrm{e}} \text {, volume of external } \\
\text { liquid; } V_{\mathrm{p}} \text {, particle volume }\left(\mathrm{cm}^{3}\right)\end{array}$ \\
\hline$W_{\mathrm{u}}$ & initial mass of fertilizer per particle (g) \\
\hline \multicolumn{2}{|c|}{ Greek symbols } \\
\hline$\alpha_{1}$ & defined by Eq. (4) \\
\hline$\beta$ & defined by Eq. (8a) \\
\hline$\rho_{\mathrm{u}}$ & density of fertilizer or urea $\left(\mathrm{g} / \mathrm{cm}^{3}\right)$ \\
\hline
\end{tabular}

core and fertilizer concentration in the core is at the saturation concentration, $C_{\mathrm{sat}}, t_{\mathrm{s}}$ is the time at which the solid fertilizer in the core has just been exhausted; and (3) for $t>t_{\mathrm{s}}$, no more solid fertilizer is in the core and fertilizer concentration in the core decreases with time.

Fertilizer release from a scoop of coated pure fertilizer beads in a well stirred liquid of volume $V_{\mathrm{e}}$ follows, in general, the stages described above. In this analysis, the first stage is neglected and only the second and third stages are considered. Details of the analysis are given in Appendix A. In the following, the results that are directly useful in analyzing experimental data are summarized.

1. For $t_{0} \leq t \leq t_{\mathrm{s}}$

$$
\begin{aligned}
& \ln (1-F)=-n N_{1}\left(t-t_{0}\right) \\
& F \equiv \frac{K_{\mathrm{b}} C_{\mathrm{e}}}{K_{\mathrm{a}} C_{\mathrm{sat}}} \\
& n N_{1} \equiv n \frac{4 \pi}{V_{\mathrm{e}}} \frac{D}{K_{\mathrm{a}}} \frac{a b}{a-b} \\
& \alpha_{1} \equiv \frac{K_{\mathrm{b}} V_{\mathrm{c}}}{K_{\mathrm{a}} V_{\mathrm{e}}}
\end{aligned}
$$

$$
\begin{aligned}
& \frac{M_{t}}{M_{t_{\infty}}}=\frac{1+n \alpha_{1}}{n \alpha_{1}} \frac{1}{\beta}\left[1-\exp \left(-n N_{1}\left(t-t_{0}\right)\right)\right] \\
& \frac{\mathrm{d}\left(M_{t} / M_{t_{\infty}}\right)}{\mathrm{d} t}=\frac{1+n \alpha_{1}}{n \alpha_{1}} \frac{n N_{1}}{\beta} \exp \left(-n N_{1}\left(t-t_{0}\right)\right)
\end{aligned}
$$

2. At $t=t_{\mathrm{S}}$

$$
\begin{aligned}
& t_{\mathrm{s}}-t_{0}=-\frac{1}{n N_{1}} \ln \left[1-n \alpha_{1}(\beta-1)\right] \\
& \beta \equiv \frac{\rho_{\mathrm{u}}}{C_{\mathrm{sat}}}
\end{aligned}
$$

3. For $t>t_{\mathrm{s}}$

$$
\begin{aligned}
& \frac{M_{t}}{M_{t_{\infty}}}=\frac{1+n \alpha_{1}}{\beta}[(\beta-1) \\
& \left.\quad+\frac{1-n \alpha_{1}(\beta-1)}{1+n \alpha_{1}}\left[1-\exp \left(-\overline{N_{1}}\left(t-t_{\mathrm{s}}\right)\right)\right]\right] \\
& \frac{\mathrm{d}\left(M_{t} / M_{t_{\infty}}\right)}{\mathrm{d} t}=\frac{1-n \alpha_{1}(\beta-1)}{\beta} \overline{N_{1}} \exp \left[-\overline{N_{1}}\left(t-t_{\mathrm{s}}\right)\right] \\
& \overline{N_{1}} \equiv n N_{1}+\frac{n N_{1}}{n \alpha_{1}}
\end{aligned}
$$

In the above equations, particle number, $n$, always appears in product form, that is, as $n \alpha_{1}$ and $n N_{1}$. Eq. (1) on a semi-log paper is a straight line with slope $-n N_{1}$. Slope $-n N_{1}$ can be determined by using experimental $C_{\mathrm{e}}$ vs. $t$ data with $F$ calculated according to Eq. (2) for an assumed $K_{\mathrm{b}} / K_{\mathrm{a}}$. Eqs. (3), (4), (8a), and (11) define the parameters as indicated. $\beta$, according to Eq. (8a), is a known quantity for a specified system. Eq. (7) calculates time $t_{\mathrm{s}}-t_{0}$. Eqs. (5) and (9) calculate fractional cumulative release before and after $t_{\mathrm{s}}$, and Eqs. (6) and (10), fractional release rate. In these calculations, only three parameters, $\beta, n N_{1}$, and $n \alpha_{1}$, need to be known.

Parameter $n \alpha_{1}$ may be expressed as follows:

$n \alpha_{1}=n \frac{K_{\mathrm{b}} K_{\mathrm{c}}}{K_{\mathrm{a}} V_{\mathrm{e}}}=\frac{K_{\mathrm{b}}}{K_{\mathrm{a}}} \frac{n V_{\mathrm{c}} \rho_{\mathrm{u}}}{V_{\mathrm{e}} \rho_{\mathrm{u}}}=\frac{K_{\mathrm{b}}}{K_{\mathrm{a}}} \frac{\left(n W_{\mathrm{u}}\right)}{V_{\mathrm{e}} \rho_{\mathrm{u}}}$

where $V_{\mathrm{e}}$ is known experimentally and $\rho_{\mathrm{u}}$, fertilizer density, is known. $V_{\mathrm{c}}$ represents the volume of one core bead. Product $V_{\mathrm{c}} \rho_{\mathrm{u}}$ is equal to $W_{\mathrm{u}}$, the initial weight of solid fertilizer in one particle. In the case that particle number, $n$, and core radius, $b$, are known, $n \alpha_{1}$ may be calculated by the second term in Eq. (12) for a given $K_{\mathrm{b}} / K_{\mathrm{a}}$. However, as are often so in practical cases, $n$, and $b$ of a scoop are unknown. In such case, as

$n W_{\mathrm{u}}=($ total drug wt. assayed $)$

$n W_{\mathrm{u}}$ can be determined experimentally. Manufacturer's data may also be consulted. Then, $n \alpha_{1}$ may be calculated by the last term in Eq. (12) for a given $K_{\mathrm{b}} / K_{\mathrm{a}}$.

\section{Method of application}

Experimental release data from a scoop of coated pure fertilizer beads may be analyzed by the following trial and error method. First, a value is guessed for $K_{\mathrm{b}} / K_{\mathrm{a}}$. Then, from 


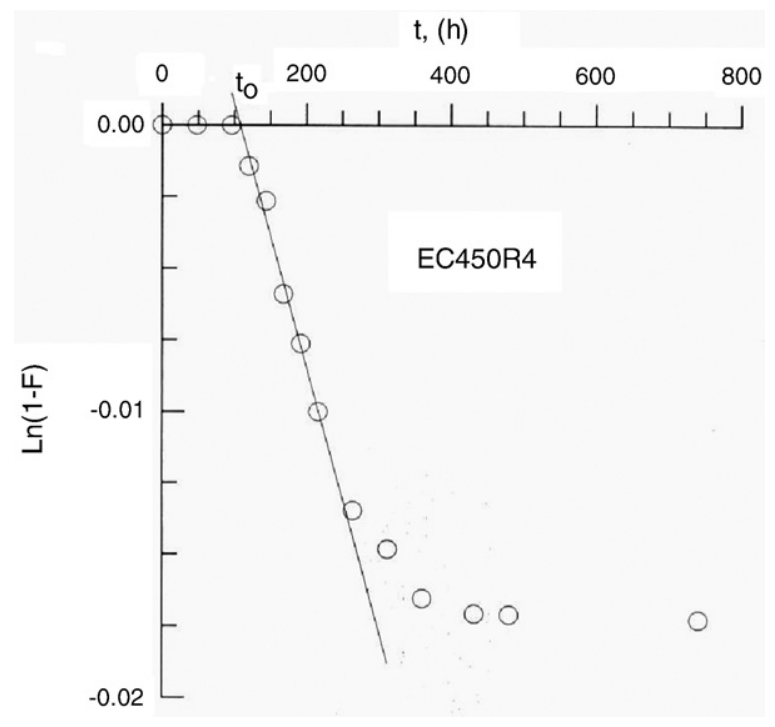

Fig. 1. Fitting experimental data to Eq. (1), for EC450R4. Slope and intercept $t_{0}$ are listed in Table 1.

experimentally obtained $C_{\mathrm{e}}$ vs. $t$ data, $F$ are calculated according to Eq. (2) and a plot, $(1-F)$ vs. $t$, is constructed on a semi-log paper. The data in the second release stage, which can be discerned easily because of the difference in the trend of the data points, is then fitted with a straight line. Fig. 1 shows an example with sample EC450R4. Time $t_{0}$ and slope $-n N_{1}$ are thus determined. Next, $n \alpha_{1}$ is found by Eqs. (13) and (12).

For a given release system, $\beta$ can be calculated by Eq. (8a). $\left(t_{\mathrm{s}}-t_{0}\right)$ is then calculated by Eq. (7). With $n N_{1}$ and $n \alpha_{1}$ known, $\overline{N_{1}}$ is calculated by Eq. (11). Fractional cumulative release curve over the entire release life is then calculated by Eqs. (5) and (9). This curve may be checked with the experimental data. If the agreement is good and the material balance is correct, the $K_{\mathrm{b}} / K_{\mathrm{a}}$ and the slope $-n N_{1}$ are accepted; if not, a new guess is taken for $K_{\mathrm{b}} / K_{\mathrm{a}}$ and the process is repeated. Fractional release rate curve over the entire release life is then calculated by Eqs. (6) and (10). The group, $n\left(D / K_{\mathrm{a}}\right)(a b /(a-b))$, representing the mixed effects of variables $n, D / K_{\mathrm{a}}, a$ and $b$, can be determined from Eq. (3). Thus, it has been shown that time $t_{\mathrm{s}}$, fractional cumulative release, and fractional release rate may be calculated without knowing particle number $n$ and particle radii $a$ and $b$.

One group of variable that may bring further information about the scoop is the $D / K_{\mathrm{b}}$ of the scoop. However, to find $\left(D / K_{\mathrm{b}}\right)$, it is necessary to know $a, b$, and $n$. If these are available, then, from $n\left(D / K_{\mathrm{a}}\right)(a b /(a-b))$ which has already been determined, the $D / K_{\mathrm{b}}$ can be calculated. For particles which were sieved before and after coating, $n$ can be determined by counting, and radii, $a$ and $b$, may be evaluated by experimental measurement of the coating thickness and particles size.

\section{Experiment}

A small Wurster type bottom spray coating unit with a draft tube was designed and setup for coating. Urea beads, 10/12 mesh (ASTM standard), were spray coated respectively with $5 \%(\mathrm{w} / \mathrm{v})$ acetone solutions of Ethocel 45Std (Dow Chemical) and CAP-482-0.5 (Eastman Chemical). Temperature of the coating solution was kept at $30{ }^{\circ} \mathrm{C}$. Bed temperature, depending on the position, varied from near 51 to 32 . Particles were sieved before and after coating.

For release test, $2 \mathrm{~g}$ of a sample were placed inside a $125 \mathrm{~mL}$ flask containing $100 \mathrm{~mL}$ distilled water. The flask was mounted on an orbital shaker at $120 \mathrm{rpm}$. The release proceeded at $25{ }^{\circ} \mathrm{C}$. The urea released was analyzed by the conductivity method (Chin and Kroontje, 1961).

\section{Results and discussion}

The results of experiments and analysis are summarized and discussed as follows.

Table 1

The result of application of the analysis to the experiments $\left(C_{\mathrm{sat}}=0.632 \mathrm{~g} / \mathrm{mL}, \rho_{\mathrm{u}}=1.335 \mathrm{~g} / \mathrm{mL}, V_{\mathrm{e}}=100 \mathrm{~mL}\right)$

\begin{tabular}{|c|c|c|c|c|c|c|c|c|c|c|c|c|}
\hline \multirow[t]{3}{*}{ No. } & \multicolumn{2}{|l|}{ Sample } & \multirow[t]{3}{*}{$n W_{\mathrm{u}}(\mathrm{g})$} & \multirow[t]{3}{*}{$K_{\mathrm{b}} / K_{\mathrm{a}}(-)$} & \multicolumn{7}{|c|}{ Parameters for Eqs. (5), (6), (9), (10) } & \multirow{3}{*}{$\begin{array}{l}\left(D / K_{\mathrm{a}}\right)(\mathrm{nab} / \\
(\mathrm{a}-\mathrm{b}))(1 / \mathrm{s})\end{array}$} \\
\hline & \multirow[t]{2}{*}{ Type } & \multirow[t]{2}{*}{ Wt. (g) } & & & \multicolumn{2}{|c|}{ Experimental data } & \multirow[t]{2}{*}{$n \alpha_{1}(-)$} & \multirow[t]{2}{*}{$\beta(-)$} & \multirow[t]{2}{*}{$t_{\mathrm{s}}-t_{0}(\mathrm{~h})$} & \multirow[t]{2}{*}{$t_{\mathrm{s}}(\mathrm{h})$} & \multirow[t]{2}{*}{$N_{1}(1 / \mathrm{h})$} & \\
\hline & & & & & $-n N_{1}(1 / \mathrm{h})$ & $t_{0}(\mathrm{~h})$ & & & & & & \\
\hline 1 & EC150R1 & 2 & 1.932 & 2.5 & $2.17 \mathrm{E}-3$ & 1.0 & 0.03619 & 2.1112 & 18.9 & 19.9 & 0.06214 & 4.797E-6 \\
\hline 2 & EC150R2 & 2 & 1.912 & 3.5 & $2.96 \mathrm{E}-3$ & 1.0 & 0.05014 & 2.1112 & 19.4 & 20.4 & 0.06200 & $6.543 \mathrm{E}-6$ \\
\hline 3 & EC150R3 & 2 & 1.920 & 4 & $2.89 \mathrm{E}-3$ & 1.0 & 0.05754 & 2.1112 & 22.9 & 23.9 & 0.05312 & $6.388 \mathrm{E}-6$ \\
\hline 4 & EC300R1 & 2 & 1.189 & 2.5 & 4.64E-4 & 4.5 & 0.02226 & 2.1112 & 54.0 & 58.5 & 0.02131 & $1.026 \mathrm{E}-6$ \\
\hline 7 & EC450R4 & 2 & 0.5566 & 2 & $9.22 \mathrm{E}-5$ & 108 & 0.008339 & 2.1112 & 101.1 & 209.2 & 0.01110 & $2.038 \mathrm{E}-7$ \\
\hline 8 & EC450R5 & 2 & 0.5686 & 2 & $1.10 \mathrm{E}-4$ & 87.0 & 0.008518 & 2.1112 & 86.5 & 173.5 & 0.01297 & $2.432 \mathrm{E}-7$ \\
\hline 9 & EC450R6 & 2 & 0.5725 & 2 & $1.17 \mathrm{E}-4$ & 82.9 & 0.008577 & 2.1112 & 81.9 & 164.8 & 0.01357 & $2.586 \mathrm{E}-7$ \\
\hline 10 & CAP150R1 & 2 & 1.873 & 2.5 & $4.88 \mathrm{E}-3$ & 0.0 & 0.03507 & 2.1112 & 8.2 & 8.2 & 0.14403 & $1.079 \mathrm{E}-5$ \\
\hline 11 & CAP150R2 & 2 & 1.861 & 3 & $5.53 \mathrm{E}-3$ & 0.0 & 0.04182 & 2.1112 & 8.6 & 8.6 & 0.13778 & $1.222 \mathrm{E}-5$ \\
\hline 12 & CAP150R3 & 2 & 1.849 & 3 & $5.51 \mathrm{E}-3$ & 0.0 & 0.04155 & 2.1112 & 8.6 & 8.6 & 0.13813 & $1.218 \mathrm{E}-5$ \\
\hline
\end{tabular}




\subsection{Experiments and analysis}

Application of the analysis to the results of experiments is shown step by step in Table 1 . Columns 1 and 2 show sample number and sample type. For the later, the first two or three letters show the coating material, and the next three digits show a number which is proportional to the mass $f$ coating material sprayed. The last two letters show run number. Column 3 shows that $2 \mathrm{~g}$ of a sample was used in each release experiment. Column 4 shows $n W_{\mathrm{u}}$, the weight of urea in $2 \mathrm{~g}$ of sample, evaluated as shown by Eq. (13). Column 5 shows the magnitudes of $K_{\mathrm{b}} / K_{\mathrm{a}}$ used. Columns 6 and 7 show, respectively, slope $-n N_{1}$ and intercept $t_{0}$ determined from experimental data by a plot like Fig. 1. Columns 8-12 show $n \alpha_{1}, \beta, t_{\mathrm{s}}-t_{0}, t_{\mathrm{s}}$ and $\overline{N_{1}}$ determined as indicated. The last column lists $n\left(D / K_{\mathrm{a}}\right)(a b /(a-b))$ calculated using Eq. (3). Thus, the parameters needed for computing a fractional
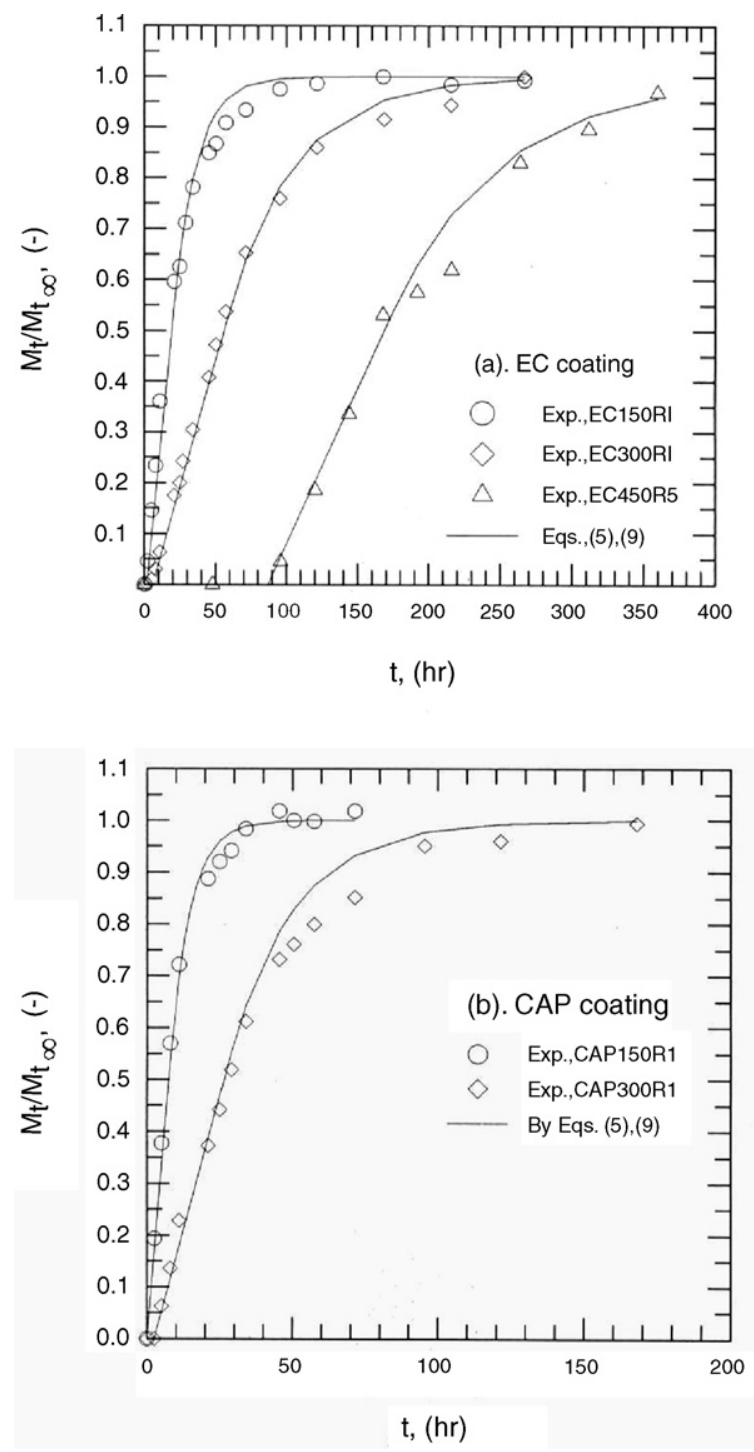

Fig. 2. Comparison of the experimental and calculated fractional cumulative release for scoops of spray coated urea beads releasing in water. For each sample, the solid line is calculated by Eq. (5) $\left(t<t_{\mathrm{s}}\right)$ and Eq. (9) $\left(t>t_{\mathrm{s}}\right)$, where $t_{\mathrm{s}}$ are listed in Table 1. (a) EC coating and (b) CAP coating. cumulative release curve and a fractional release rate curve have been obtained as shown without requiring information for particle number and radii.

Experimental and calculated fractional cumulative release for EC and CAP coatings are shown in Fig. 2. Good agreement has been obtained. The calculated fractional release rate curves are shown in Fig. 3. The $t_{0}$ of most samples were small and were ignored except EC450R4-6 for which $t_{0}$ exceeded $81 \mathrm{~h}$. Generally speaking, the rate rises from zero to a fairly constant rate within time $t_{0}$, maintains a fairly constant rate for time length $t_{\mathrm{s}}-t_{0}$, and falls after $t_{\mathrm{s}}$. Particles with EC coating resulted in lower fairly constant rate over a longer time than particles with CAP coating which gave a fairly high constant rate over a shorter time. Urea release is faster by EC coating than by CAP coating. Particles with either coating gave long tailing time after $t_{\mathrm{s}}$. This is not due to the coatings but to the system (urea and water) which is a system of high solubility
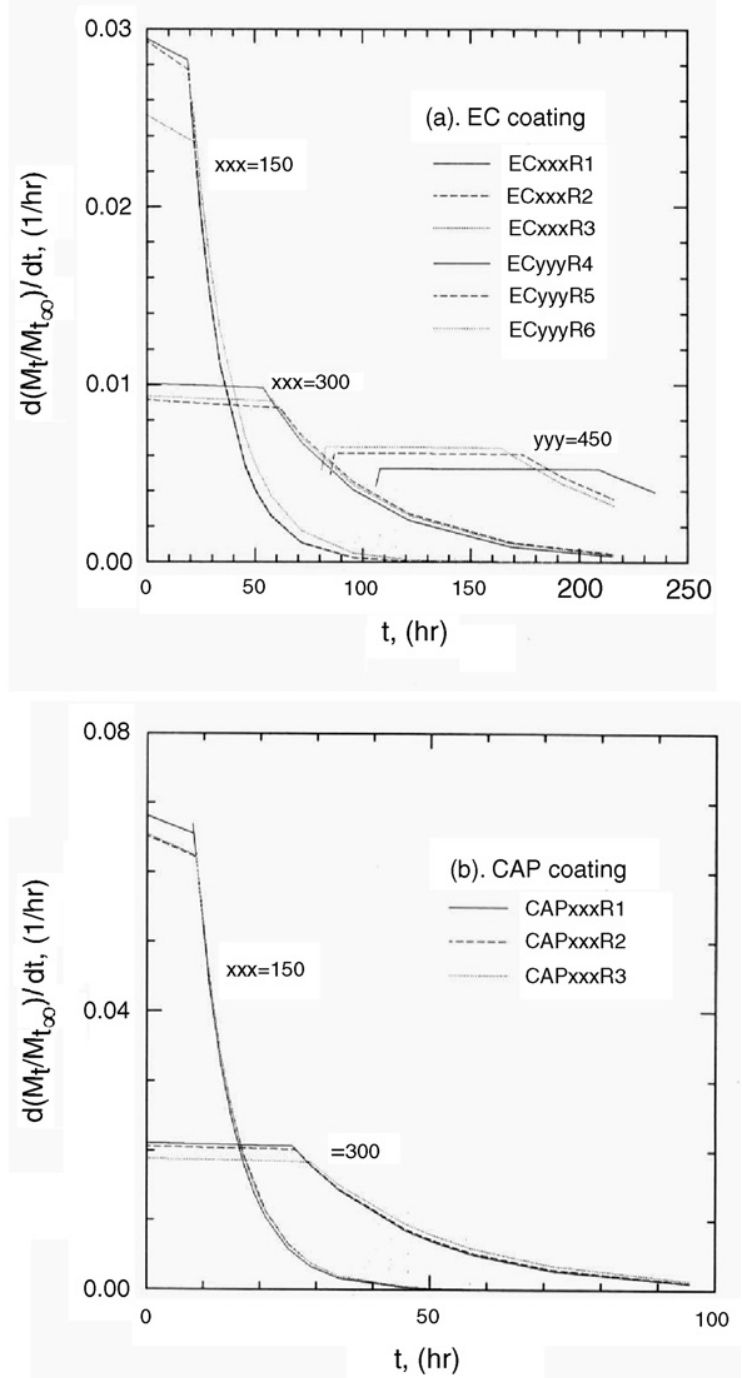

Fig. 3. Fractional release rate curves calculated for scoops of spray coated urea beads releasing in water, by Eq. (6) $\left(t<t_{\mathrm{s}}\right)$ and Table 1. (a) EC coating and (b) CAP coating. 
Table 2

Calculation for $D / K_{\mathrm{b}}$

\begin{tabular}{|c|c|c|c|c|c|c|c|c|c|c|c|}
\hline No. & Sample & $n(-)$ & $n W_{\mathrm{u}}(\mathrm{g})$ & $W_{\mathrm{u}} \times 100(\mathrm{~g})$ & $\begin{array}{l}b \times 100 \\
(\mathrm{~cm})\end{array}$ & $\begin{array}{l}(\mathrm{a}-\mathrm{b}) \times 100 \\
(\mathrm{~cm})\end{array}$ & mesh & $a(\mathrm{~cm})$ & $a / b(-)$ & $\begin{array}{l}D / K_{\mathrm{a}} \times 10^{-8} \\
\left(\mathrm{~cm}^{2} / \mathrm{s}\right)\end{array}$ & $\begin{array}{l}D / K_{\mathrm{b}} \times 10^{-8} \\
\left(\mathrm{~cm}^{2} / \mathrm{s}\right)\end{array}$ \\
\hline 1 & EC150R1 & 486 & 1.932 & 0.3976 & 8.925 & 0.889 & $10 / 12$ & 0.098 & 1.100 & 1.0017 & 0.4007 \\
\hline 2 & EC150R2 & 481 & 1.912 & 0.3976 & 8.925 & 0.889 & $10 / 12$ & 0.098 & 1.100 & 1.3805 & 0.3944 \\
\hline 3 & EC150R3 & 483 & 1.920 & 0.3976 & 8.925 & 0.889 & $10 / 12$ & 0.098 & 1.100 & 1.3422 & 0.3356 \\
\hline 4 & EC300R1 & 299 & 1.189 & 0.3976 & 8.925 & 2.642 & $8 / 10$ & 0.116 & 1.296 & 0.8780 & 0.3512 \\
\hline 5 & EC300R2 & 296 & 1.177 & 0.3976 & 8.925 & 2.642 & $8 / 10$ & 0.116 & 1.296 & 1.5577 & 0.3115 \\
\hline 6 & EC300R3 & 302 & 1.201 & 0.3976 & 8.925 & 2.642 & $8 / 10$ & 0.116 & 1.296 & 0.9718 & 0.3239 \\
\hline 7 & EC450R4 & 140 & 0.5566 & 0.3976 & 8.925 & 4.953 & $7 / 8$ & 0.139 & 1.555 & 0.5821 & 0.2910 \\
\hline 8 & EC450R5 & 143 & 0.5686 & 0.3976 & 8.925 & 4.953 & $7 / 8$ & 0.139 & 1.555 & 0.6800 & 0.3400 \\
\hline 9 & EC450R6 & 144 & 0.5725 & 0.3976 & 8.925 & 4.953 & $7 / 8$ & 0.139 & 1.555 & 0.7181 & 0.3590 \\
\hline 10 & CAP150R1 & 471 & 1.873 & 0.3976 & 8.925 & 0.711 & $10 / 12$ & 0.096 & 1.080 & 1.8943 & 0.7577 \\
\hline 11 & CAP150R2 & 468 & 1.861 & 0.3976 & 8.925 & 0.711 & $10 / 12$ & 0.096 & 1.080 & 2.1591 & 0.7197 \\
\hline 12 & CAP150R3 & 465 & 1.849 & 0.3976 & 8.925 & 0.711 & $10 / 12$ & 0.096 & 1.080 & 2.1659 & 0.7220 \\
\hline 13 & CAP300R1 & 277 & 1.101 & 0.3976 & 8.925 & 2.489 & $8 / 10$ & 0.114 & 1.279 & 1.4095 & 0.7048 \\
\hline 14 & CAP300R2 & 275 & 1.093 & 0.3976 & 8.925 & 2.489 & $8 / 10$ & 0.114 & 1.279 & 1.3771 & 0.6886 \\
\hline 15 & CAP300R3 & 275 & 1.093 & 0.3976 & 8.925 & 2.489 & $8 / 10$ & 0.114 & 1.279 & 1.5673 & 0.6269 \\
\hline
\end{tabular}

(Lu, 1994). Figs. 2 and 3 may thus be obtained without knowing particle number and radii of the scoop.

\section{2. $D / K_{b}$ of a scoop}

The representative $D / K_{\mathrm{b}}$ of a scoop of particles may be determined as shown in Table 2. Column 3 of Table 2 shows the number of particles counted in $2 \mathrm{~g}$ of sample. Column 4 shows $n W_{\mathrm{u}}$ which has already been shown in Table 1 . As $n$ is also the number of core beads, thus, $W_{\mathrm{u}}$, the representative weight of one urea bead for the scoop, may be found by dividing column 4 by column. Column 5 shows the result. As the density of urea is known, $b$ can be calculated as shown in column.

It should be noted that $b$ may also be estimated from mesh size and sieve openings. However, for thinly coated particles, like sample no. 1, 2, 3 and 10,11,12, most coated particles still fall in $10 / 12$ mesh, the same as for the core beads. Thus, $b$ is estimated as has already been explained. The percentage relative difference between the $b$ in Table 2 and the average sieve openings (10/12 mesh) is $3.5 \%$, and with the average of direct measurement, is $2.1 \%$.

Column 7 of Table 2 shows the averaged coating thickness measured by a $60 \times$ precision magnifier. Column 8 shows mesh size of coated particles. Column 9 shows radius of coated particle $a$ obtained by adding columns 6 and 7. $a$ may also be estimated by the average sieve opening. The percentage difference between these two $a$ is less than about 9\%. It is recommended that coating thickness be determined by direct measurement and not by subtraction of $b$ from $a$, or vice versa. The later can result in large errors, particularly for thin coating. Column 10 shows radius ratio. Columns 11 and 12 show $D / K_{\mathrm{a}}$ and $D / K_{\mathrm{b}}$, calculated as indicated.

The $D / K_{\mathrm{b}}$ evaluated as above is plotted against coating thickness, as shown in Fig. 4. The magnitudes of $D / K_{\mathrm{b}}$ obtained for thick coatings are more easily consistent with each other than those for thin coatings. Care must be taken for coating thickness below $0.01 \mathrm{~cm}$. Fig. 4 shows that the representative
$D / K_{\mathrm{b}}$ for urea in spray coating layer is around $3.5 \times 10^{-8} \mathrm{~cm}^{2} / \mathrm{s}$ for EC and $7 \times 10^{-8} \mathrm{~cm}^{2} / \mathrm{s}$ for CAP.

\subsection{General discussion}

Inspection of Eqs. (5), (9), (6), (10), and (A-8) and (A-19) show that in the analysis, fertilizer release from a scoop of particles is equivalent to each particle releasing in a liquid volume $V_{\mathrm{e}} / n$. That is, fertilizer release from $n$ particles in a liquid of volume $V_{\mathrm{e}}$ is equivalent to fertilizer release from a single particle in a liquid of volume $V_{\mathrm{e}} / n$. When $V_{\mathrm{e}} / n$ is large, the condition of a perfect sink is justified, the effect of particle number on the release may be neglected, and relatively constant release rate is maintained from $t_{0}$ to $t_{\mathrm{s}}$. However, when $V_{\mathrm{e}} / n$ is small, the effect of $n$ appears and the release rate from $t_{0}$ to $t_{\mathrm{s}}$ may show considerable changes.

For small $V_{\mathrm{e}} / n$, there are other complications. Besides the increased interference among the particles, other practical

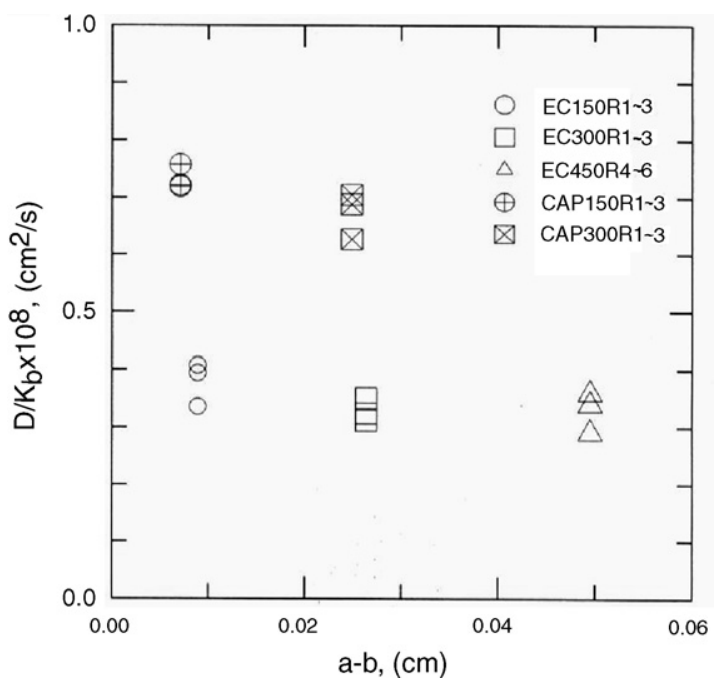

Fig. 4. $D / K_{\mathrm{b}}$ obtained for scoops of spray coated urea beads releasing in water at $25{ }^{\circ} \mathrm{C}$. 
problems, like methods for good mixing and rupture of particles by friction and collision, arise. In the case that the above problems may be ignored, there is the limiting $V_{\mathrm{e}} / n$ at which the system ends release at $t=t_{\mathrm{s}}$. Below this limiting $V_{\mathrm{e}} / n$, fertilizer release ends with solid fertilizer still present in the core. In laboratory work, these situations are easily avoided by using sufficient amount of liquid. In applications, such situation could be encountered if particles are applied in a very limited environment.

It should also be pointed out that for very small core beads, coating thickness should be kept thin relative to the core radius if a fairly constant release rate is to be obtained. A very small bead with very thick coating may lead to the situation that exhaustion of solid fertilizer in a core occurs before the development of a pseudo-steady state concentration profile.

\section{Conclusion}

The fractional cumulative release and fractional release rate curves of a scoop of spray coated pure fertilizer beads releasing in a well stirred liquid may be determined without knowing the particle number and radii. The representative $D / K_{\mathrm{a}}$ for the scoop may also be determined once the representative coating thickness and core radius of the scoop are estimated.

\section{Acknowledgement}

This project (NSC 85-2214-E002-026) was supported by National Science Council, ROC.

\section{Appendix A}

\section{A.1. Derivation of the equations}

The basic equation for fertilizer concentration in the coating layer, $C$, and the conditions are

$$
\begin{aligned}
& \frac{\partial(r C)}{\partial t}=D \frac{\partial^{2}(r C)}{\partial r^{2}}, \quad b<r<a \\
& C(b, t)=\frac{C_{\mathrm{sat}}}{K_{\mathrm{b}}}, \quad t_{0} \leq t \leq t_{\mathrm{s}} \\
& C(b, t)=\frac{C_{\mathrm{c}}(t)}{K_{\mathrm{b}}}, \quad t>t_{\mathrm{s}} \\
& C(a, t)=\frac{C_{\mathrm{e}}(t)}{K_{\mathrm{a}}}, \quad t>0
\end{aligned}
$$

$t_{0}$ is assumed to be the time that the external liquid has infiltrated the coating layer and that the pseudo-steady state concentration profile is established in the coating layer. Thus, $C\left(b, t<t_{0}\right)=0$ is assumed.
With the assumption that pseudo-steady state exists for $t \geq t_{0}$, the pseudo-steady state concentration profile for $t \geq t_{0}$ is

$C(r, t)=\frac{a C(a, t)-b C(b, t)}{a-b}+\frac{1}{r} \frac{a b}{a-b}[C(b, t)-C(a, t)]$

With Fick's law, then the rate of diffusion is

$J\left(4 \pi r^{2}\right)=-D\left(\frac{\partial C}{\partial r}\right)\left(4 \pi r^{2}\right)=4 \pi D \frac{a b}{a-b}[C(b, t)-C(a, t)]$

The time derivatives of fertilizer concentration in the external liquid and in the core may be obtained, respectively, by material balance and by Eq. (A-4). The results are

$\frac{\mathrm{d} C_{\mathrm{e}}}{\mathrm{d} t}=\frac{n J\left(4 \pi r^{2}\right)}{V_{\mathrm{e}}}=n \frac{4 \pi D}{V_{\mathrm{e}}} \frac{a b}{a-b}[C(b, t)-C(a, t)]$

$\frac{\mathrm{d} C_{\mathrm{c}}}{\mathrm{d} t}=\frac{4 \pi D}{V_{\mathrm{e}}} \frac{a b}{a-b}[C(b, t)-C(a, t)]$

1. When $t_{0} \leq t \leq t_{\mathrm{s}}$

Notice that $t_{0} \leq t \leq t_{\mathrm{s}}, C_{\mathrm{c}}(t)=C_{\mathrm{sat}}$. Eq. (A-5a) then becomes

$\frac{\mathrm{d} C_{\mathrm{e}}}{\mathrm{d} t}=n N_{1}\left(\frac{K_{\mathrm{a}}}{K_{\mathrm{b}}} C_{\mathrm{sat}}-C_{\mathrm{e}}\right)$

where

$n N_{1} \equiv n \frac{4 \pi}{V_{\mathrm{e}}} \frac{D}{K_{\mathrm{a}}} \frac{a b}{a-b}$

Eq. (A-6), after separation of variables, is integrated from $t=t_{0}, C_{\mathrm{e}}=0$ to $t=t, C_{\mathrm{e}}=C_{\mathrm{e}}$, the result is

$\ln \left(1-\frac{K_{\mathrm{b}} C_{\mathrm{e}}}{K_{\mathrm{a}} C_{\mathrm{sat}}}\right)=-n N_{1}\left(t-t_{0}\right)$

or

$\frac{C_{\mathrm{e}}}{C_{\mathrm{sat}}}=\frac{K_{\mathrm{a}}}{K_{\mathrm{b}}}\left[1-\exp \left(-n N_{1}\left(t-t_{0}\right)\right)\right]$

Eq. (A-7) may be written as

$\ln (1-F)=-n N_{1}\left(t-t_{0}\right)$

where

$F \equiv \frac{K_{\mathrm{b}} C_{\mathrm{e}}}{K_{\mathrm{a}} C_{\mathrm{sat}}}$

on a semi-log plot, Eq. (1) represents a straight line with slope $\left(-n N_{1}\right)$.

To fine cumulative release, $M_{t}$, as

$M_{t}=V_{\mathrm{e}} C_{\mathrm{e}}$

by substituting the $C_{\mathrm{e}}$ in Eq. (A-8) into the above equation, obtain

$M_{t}=\frac{V_{\mathrm{c}} C_{\mathrm{sat}}}{\alpha_{1}}\left[1-\exp \left(-n N_{1}\left(t-t_{0}\right)\right)\right]$ 
where

$\alpha_{1} \equiv \frac{K_{\mathrm{b}} V_{\mathrm{c}}}{K_{\mathrm{a}} V_{\mathrm{e}}}$

The fractional cumulative release can be obtain by dividing the above equation by $M_{t_{\infty}}$, i.e., Eq. (A-21) which is derived later. The result is

$\frac{M_{t}}{M_{t_{\infty}}}=\frac{1+n \alpha_{1}}{n \alpha_{1}} \frac{1}{\beta}\left[1-\exp \left(-n N_{1}\left(t-t_{0}\right)\right)\right]$

where $\beta$ is defined by Eq. (8a).

The fractional release rate is obtained by differentiating Eq. (5) with respect to time, i.e.

$\frac{\mathrm{d}\left(M_{t} / M_{t_{\infty}}\right)}{\mathrm{d} t}=\frac{1+n \alpha_{1}}{n \alpha_{1}} \frac{n N_{1}}{\beta} \exp \left(-n N_{1}\left(t-t_{0}\right)\right)$

2. At $t=t_{\mathrm{s}}$

At $t_{\mathrm{s}}$, the amount of fertilizer left in a core is $V_{\mathrm{c}} C_{\text {sat }}$ and the cumulative release is $M_{t_{\mathrm{s}}}$. As $W_{\mathrm{u}}$ is the initial amount of fertilizer in a core, $M_{t_{\mathrm{s}}}$ is expressed by

$M_{t_{\mathrm{s}}}=n\left(W_{\mathrm{u}}-V_{\mathrm{c}} C_{\mathrm{sat}}\right)$

Equate Eq. (A-11) to Eq. (A-10) at $t_{\mathrm{s}}$ and solve the resulting equation for $t_{\mathrm{s}}$ to find

$t_{\mathrm{s}}-t_{0}=-\frac{1}{n N_{1}} \ln \left[1-n \alpha_{1}(\beta-1)\right]$

where

$\beta=\frac{W_{\mathrm{u}}}{V_{\mathrm{c}} C_{\mathrm{sat}}}=\frac{\rho_{\mathrm{u}}}{C_{\mathrm{sat}}}$

3. For $t>t_{\mathrm{s}}$

By material balance for the fertilizer and by Eq. (A-5a), obtain

$-n V_{\mathrm{c}} \frac{\mathrm{d} C_{\mathrm{c}}}{\mathrm{d} t}=V_{\mathrm{e}} \frac{\mathrm{d} C_{\mathrm{e}}}{\mathrm{d} t}=n\left(4 \pi D \frac{a b}{a-b}\right)[C(b, t)-C(a, t)]$

By using Eqs. (A-2b), (3) and (4), the above equation becomes

$-\frac{\mathrm{d} C(b, t)}{\mathrm{d} t}=\frac{N_{1}}{\alpha_{1}}[C(b, t)-C(a, t)]$

Similarly, by using Eqs. (A-2c), (3) and (4), Eq. (A-12) becomes

$\frac{\mathrm{d} C(a, t)}{\mathrm{d} t}=n N_{1}[C(b, t)-C(a, t)]$

Addition of the above two equations results in

$-\frac{\mathrm{d}[C(b, t)-C(a, t)]}{\mathrm{d} t}=\overline{N_{1}}[C(b, t)-C(a, t)]$ where

$\overline{N_{1}} \equiv n N_{1}+\frac{n N_{1}}{n \alpha_{1}}$

Eq. (A-15), after separation of variables, is integrated from $t=t_{\mathrm{s}}$ to $t=t$, the result is

$C(b, t)-C(a, t)=\left[C\left(b, t_{\mathrm{s}}\right)-C\left(a, t_{\mathrm{s}}\right)\right] \exp \left\lfloor-\overline{N_{1}}\left(t-t_{\mathrm{s}}\right)\right\rfloor$

substitute the above equation into Eq. (A-5a) and integration the resulting equation from $t=t_{\mathrm{s}}$ to $t=t$. With

$C\left(b, t_{\mathrm{s}}\right)=\frac{C_{\mathrm{sat}}}{K_{\mathrm{b}}}$

$C\left(a, t_{\mathrm{s}}\right)=\frac{n\left(W_{\mathrm{u}}-V_{\mathrm{c}} C_{\mathrm{sat}}\right)}{V_{\mathrm{e}} K_{\mathrm{a}}}$

the result of integration is rearranged as follows:

$$
\begin{aligned}
\frac{C_{\mathrm{e}}}{C_{\mathrm{sat}}}= & n \frac{V_{\mathrm{c}}}{V_{\mathrm{e}}}[(\beta-1) \\
& \left.+\frac{1-n \alpha_{1}(\beta-1)}{1+n \alpha_{1}}\left[1-\exp \left(-\overline{N_{1}}\left(t-t_{\mathrm{s}}\right)\right)\right]\right]
\end{aligned}
$$

cumulative release is obtained from Eqs. (A-19) and (A-9), i.e.,

$$
\begin{aligned}
M_{t}= & n V_{\mathrm{c}} C_{\mathrm{sat}}[(\beta-1) \\
& \left.+\frac{1-n \alpha_{1}(\beta-1)}{1+n \alpha_{1}}\left[1-\exp \left(-\overline{N_{1}}\left(t-t_{\mathrm{s}}\right)\right)\right]\right]
\end{aligned}
$$

As $t \rightarrow \infty$, the above equation becomes

$M_{t_{\infty}}=\frac{n W_{\mathrm{u}}}{1+n \alpha_{1}}$

Fractional cumulative release is then obtained as

$$
\begin{aligned}
\frac{M_{t}}{M_{t_{\infty}}}= & \frac{1+n \alpha_{1}}{\beta}[(\beta-1) \\
& \left.+\frac{1-n \alpha_{1}(\beta-1)}{1+n \alpha_{1}}\left[1-\exp \left(-\overline{N_{1}}\left(t-t_{\mathrm{s}}\right)\right)\right]\right]
\end{aligned}
$$

Fractional release rate is

$$
\frac{\mathrm{d}\left(M_{t} / M_{t_{\infty}}\right)}{\mathrm{d} t}=\frac{1-n \alpha_{1}(\beta-1)}{\beta} \overline{N_{1}} \exp \left[-\overline{N_{1}}\left(t-t_{\mathrm{s}}\right)\right]
$$

The concentration of fertilizer in the core is obtained by substituting Eq. (A-16), with Eqs. (A-17) and (A-18), into Eq. (A-5b) and integrating the resulting equation from $t=t_{\mathrm{s}}$ to $t=t$. The result is

$\frac{C_{\mathrm{c}}}{C_{\mathrm{sat}}}=1-\frac{1-n \alpha_{1}(\beta-1)}{1+n \alpha_{1}}\left[1-\exp \left[-\overline{N_{1}}\left(t-t_{\mathrm{s}}\right)\right]\right]$

As $t \rightarrow t_{\infty}$, the above equation becomes

$\frac{C_{\mathrm{c}, t_{\infty}}}{C_{\mathrm{sat}}}=\frac{n \alpha_{1} \beta}{1+n \alpha_{1}}$ 
As $C_{\mathrm{e}, t_{\infty}}=M_{t_{\infty}} / V_{\mathrm{e}}$, then with Eq. (A-23), obtain

$\frac{C_{\mathrm{c}, t_{\infty}}}{C_{\mathrm{e}, t_{\infty}}}=\frac{K_{\mathrm{b}}}{K_{\mathrm{a}}}$

\section{References}

Chen, B. H. and D. J. Lee, "Finite Element Analysis of Slow Drug Release through Deformed Coating Film: Effects of Morphology and Average Thickness of Coating Film," Int. J. Pharm., 234, 25 (2002).

Chen, P. H. and H. C. Shih, "A Chemical Kinetics Model for Oxide Chemical Mechanical Polishing," J. Chin. Inst. Chem. Engrs., 37, 401 (2006).

Chin, W. T. and W. Kroontje, "Conductivity Method for Determination of Urea," Anal. Chem., 33, 1757 (1961).

Frenning, G., A. Tunon, and G. Alderborn, "Modelling of Drug Release from Coated Granular Pellets," J. Control. Release, 92, 113 (2003).

Huang, J. F., C. H. Jien, and L. S. Lee, "Effects of Co-solvents on the Solubility of Beta-carotene in Supercritical Carbon Dioxide," J. Chin. Inst. Chem. Engrs., 37, 329 (2006).

Kanjickl, D. G. and S. T. Lopina, "Modeling of Drug Release from Polymeric Delivery Systems-A Review," Crit. Rev. Therapeutic Drug Carrier Syst., 21, 345 (2004).

Kao, C. Z. and M. H. Li, "Diffusion Coefficients of Aqueous $N, N$-diethylethanolamine, $N, N$-dimethylethanolamine, Monoisopropanolamine, Piperazine, and Sulfolane Solutions," J. Chin. Inst. Chem. Engrs., 37, 341 (2006).

Kuo, Y. C. and C. Y. Chung, "Transport of Zidovudine- and Lamivuldineloaded Polybutylcyanoacrylate and Methylmethacrylate-Sulfopropyl- methacrylate Nanoparticles across the In Vitro Blood-Brain Barrier: Characteristics of the Drug Delivery System," J. Chin. Inst. Chem. Engrs., 36, 627 (2005).

Li, S. J., Y. Shen, W. K. Li, and X. Hao, “A Common Profile for Polymer-based Controlled Releases and Its Logical Interpretation to General Release Process," J. Pharm. Sci., 9, 238 (2006).

Liao, Y. C. and D. J. Lee, "Slow Release from a Coated Sphere with Slight Deformations of Coating Film and Drug Matrix," J. Pharm. Sci., 86, 92 (1997).

Lu, S. M. and S. F. Lee, "Slow Release of Urea through Latex Film," $J$. Control. Release, 18, 171 (1992).

Lu, S. M. and S. R. Chen, "Mathematical-analysis of Drug Release from a Coated Particle," J. Control. Release, 23, 105 (1993).

Lu, S. M., "Dimensionless Presentation for Drug Release from a Coated Pure Drug Bead. 1. Analysis," Int. J. Pharm., 112, 105 (1994).

Lu, S. M. and S. R. Chen, "Controlled-release from a Coated Particle-Effects of Initial Conditions and Methods of Solution,” Int. J. Pharm., 119, 11 (1995).

Santana, D. and A. Macias-Machin, "A Model of Fluidized Bed Elutriation: Effect of Initial Mass of Fine Particles in the Bed," J. Chin. Inst. Chem. Engrs., 37, 203 (2006).

Shaviv, A., S. Raban, and E. Zaidel, "Modeling Controlled Nutrient Release from Polymer Coated Fertilizers: Diffusion Release from Single Granules," Environ. Sci. Technol., 37, 2251 (2003).

Su, W. B., J. R. Chang, T. B. Lin, and H. C. Shen, "Internal and External Mass Transfer Effects for Commercial Acid Resin Catalysts in TAME Synthesis," J. Chin. Inst. Chem. Engrs., 37, 249 (2006).

Trenkel, M. E., Controlled Release and Stabilized Fertilisers in Agriculture, IFA, Paris, France (1997). 